\title{
A PLUVIOSIDADE EM CAMPO MOURÃO NA SÉRIE 1992 A 2012
}

\author{
NiellyHneda ${ }^{(a)}$, Victor da Assunção Borsato ${ }^{(b)}$
}

(a) Departamento de Geografia, Universidade Estadual do Paraná, niellyhneda@hotmail.com

(b) Universidade Estadual do Paraná - Campus de Campo Mourão, victorb@ fecilcam.br ou 1308victor@gmail.com

\section{Eixo: Climatologia em diferentes níveis escalares: Mudanças e variabilidades}

\section{Resumo}

Este artigo abordou a climatologia das chuvas para Campo Mourão na série histórica (1992 a 2012). Foram considerados os dados mensais das chuvas registradas na Estação Climatológica de Campo Mourão e classificadas segundo Índice de Porcentagem Normal para os meses extremamente úmidos, os quais foram analisados para se interpretar a gênese da chuva. A classificação se deu por meio da Equação do Índice de Porcentagem Normal. Do total de 252 meses, 22 foram classificados como extremamente úmidos. Foram investigados as participações dos sistemas atmosféricos na região, cujo objetivo foi verificar e quantificar a participação dos sistemas atmosféricos e classificar o(s) sistema(s) gêneses das chuvas para os meses extremamente úmidos. Esses 22 meses receberam totais que oscilaram de 262,0 a 468,0 mm. Os sistemas atmosféricos gêneses para as chuvas desses meses foram os sistemas frontais e a massa Equatorial continental, principalmente. Os resultados apontaram que a maior contribuição foi consequência da passagem dos sistemas frontais pela região.

\section{Palavras chave: Climatologia Geográfica; Zona de transição; Massas de ares.}

\section{Introdução}

As chuvas intensas ocorrem a qualquer período do ano para a região de Campo Mourão - PR, ou seja, em qualquer das quatro estações. A probabilidade aumenta para o verão, considerando que nessa estação a altura registrada na região de Campo Mourão é para os anos mais chuvosos de até seis vezes o volume que é registrado no inverno, embora, não necessariamente seja o período mais úmido, pois a evapotranspiração nessa estação é elevada (MONTEIRO, 1968; ). Por isso, é importante estudar os eventos intensos para verificar se há concentração em alguma das estações do ano e também verificar qual sistema atmosférico propicia a sua ocorrência. Considerando que na região de Campo Mourão, as chuvas podem ocorrer na passagem dos sistemas frontais, assim como em episódios de chuvas convectivas, consequência da atuação de massas de ar de baixa pressão (NIMER, 1971).

Para a engenharia e planejamento que consideram os dados agrológicas, a caracterização de chuvas intensas é imprescindível à elaboração de projetos de estruturas de contenção ou do aproveitamento das águas das precipitáveis. A previsão da intensidade de precipitação é essencial para o dimensionamento de estruturas, especialmente para obras de controle da erosão, de drenagem do solo e barragens (VIEIRA, et al., 1991).

Para a Geografia, há outros aspectos que podem ser considerados. Os episódios de chuvas intensas, quase sempre são acompanhados de rajadas de ventos e também da queda de granizo que, para 
determinados períodos do ano e locais atingidos podem causar danos ambientais e principalmente econômicos (CAVALCANTE, 1983). Por outro lado, a geografia estuda também a distribuição temporal das chuvas. Para essa ciência, não é só a altura concentrada que mais interessa, mas, também a sua distribuição ao longo do tempo. As chuvas mal distribuídas ou intensas causam mais impactos negativos, comparando-se com somente a altura. As atividades agrícolas, principalmente para a região de Campo Mourão são dependentes do clima, por isso, as regularidades das chuvas influenciam diretamente no sucesso dessa atividade. Os eventos de grande intensidade podem causar erosão e a perda da adubação aplicada pelos agricultores. Os sólidos transportados das lavouras podem causar assoreamentos dos rios, assim como os fertilizantes poderão causas a eutrofização dos ribeirões (LAMPARELLI, 2004).

$\mathrm{Na}$ cidade, esses episódios poderão causar inundações nas áreas próximas aos córregos, assim como tombamento de muros residenciais, destelhamento de casas, quedas de árvores e transtorno no trânsito. Embora a primeira preocupação seja com relação à arquitetura urbana que, ao se projetar as edificações não consideram os eventos intensos, por muitos classificados como desastres naturais.

Desastre natural é definido como resultados de eventos naturais ou provocado pelo homem, sobre um ecossistema (vulnerável) causando danos ao homem e ao meio (CASTRO, 1998). Ainda segundo esse autor, há três tipos de desastres naturais, os súbitos, os graduais e de efeitos parciais. As chuvas intensas não se configuram como um desastre natural, embora os seus efeitos sim; os eventos intensos podem causar inundações.

Este trabalho teve como objetivo principal realizar o levantamento dos períodos de ocorrências de chuvas intensas para a série histórica de 1992 a 2012 em Campo Mourão, relacionando com os sistemas atmosféricos. Considerando-se que nessa região as chuvas ocorrem sob a atuação dos sistemas frontais ou da massa Equatorial continental, principalmente. Também foi possível verificar os períodos ou estação do ano mais sujeitos aos episódios de chuvas intensas, e quantificar os sistemas atmosféricos para os meses que apresentaram elevados índices de chuvas intensas.

Para a realização deste trabalho foi utilizado o Índice de Porcentagem Normal, metodologia proposta pela Embrapa (FERNANDES et al., 2009). Essa metodologia considera somente o volume de chuva registrado no mês e as "normais climatológicas". Todos os meses da série foram submetidos à equação e para os meses classificados como extremamente úmidos foram analisados a dinâmica dos sistemas atmosféricos a partir da leitura e interpretação das cartas sinóticas da Marinha do Brasil e nas imagens de satélite no canal infravermelho, disponibilizado pelo CPTEC-INPE, cujo objetivo foi identificar o sistema ou sistemas gêneses das chuvas.

A região de Campo Mourão tem na agricultura a principal atividade econômica emesmo se praticando a agricultura moderna, ela é vulnerável às condições do tempo e às condições do clima. Os episódios de chuvas intensas no período da semeadura e principalmente das colheitas podem acarretar perdas. Os 
resultados apontam os meses e a estação mais sujeitos ao "excesso" de chuva, considerando a altura registrada e as Normais Climatológica.

\section{Material e método}

A dinâmica dos sistemas atmosféricos para o Estado do Paraná foi estudada na perspectiva da Climatologia Geográfica (PÉDELABORDE, 1970). Os sistemas atmosféricos foram quantificados a partir da leitura e interpretação das cartas sinóticas da Marinha do Brasil (MAR-MIL, 2016) e nas imagens de satélite no canal infravermelho do CPTEC-INPE.

Os sistemas atmosféricos considerados foram aqueles que atuaram na região, ou seja: Sistema Frontal (SF), massa Tropical continental (mTc), massa Tropical atlântica (mTa), massa Polar atlântica (mPa), massa Equatorial continental (mEc) (VIANELLO 2000; VAREJÃO-SILVA, 2000; FERREIRA, 1989). Para o registro foram elaboradas tabelas em planilha do Excel para os meses classificados como extremamente úmidos.

O recorte temporal foi para um período de 21 anos (1992 a 2012). Os dados históricos foram fornecidos pela Estação Climatológica Principal de Campo Mourão (UNESPSAR/INMET).

Para os índices pluviométricos mensais aplicaram-se a metodologia proposta pela Embrapa (FERNANDES et al., 2009). Essa metodologia classifica as chuvas em Índices de Porcentagem Normal (Equação 1 - Tabela 1), tendo como parâmetros de comparação as "normais climatológicas".

\section{Equação 1:}

$P=\frac{\operatorname{Pr} P(\text { atual })}{\operatorname{Pr} P(\text { normal })} \times 100$

Sendo:

$\mathrm{P}=$ porcentagem da precipitação normal (\%);

$\operatorname{Prp}($ atual $)=$ precipitação medida em um dado local ou estação $(\mathrm{mm})$;

Prp $($ normal $)=$ precipitação "normal climatológica” do local ou estação considerada $(\mathrm{mm})$.

Tabela 1 - Classificação do Índice de Porcentagem Normal.

\begin{tabular}{cl}
\hline PN & Classificação \\
$\geq 100 \%$ a $90 \%$ & Extremamente úmido \\
$70 \%$ a $89,9 \%$ & Umidade alta \\
$50 \%$ a $69,9 \%$ & Umidade moderada \\
$30 \%$ a $49,9 \%$ & Umidade baixa \\
$10 \%$ a $29,9 \%$ & Umidade \\
inicial & Normal \\
$-9,9 \% \leq 0 \leq 9,9 \%$ & Seca inicial \\
$-10 \%$ a $29,9 \%$ & \\
\hline
\end{tabular}




\begin{tabular}{|c|c|}
\hline $\begin{array}{l}\text { XVII Simpósio Brasileiro } \\
\frac{\text { de Geografia Fisica Aplicada }}{\text { I Congresso Nacional }} \\
\text { de Geografia Fisica }\end{array}$ & $\begin{array}{l}\text { OS DESAFIOS DA GEOGRAFIA FÍSICA NA FRONTEIRA DO CONHECIMENTO } \\
\text { Instituto de Geociências - Unicamp } \\
\text { Campinas - SP } \\
28 \text { de Junho à } 02 \text { de Julho de } 2017\end{array}$ \\
\hline $\begin{array}{c}-30 \% \text { a } 49,9 \% \\
-50 \% \text { a } 69,9 \% \\
\text { moderada } \\
-70 \% \text { a } 89,9 \% \\
-90 \% \text { a } \leq-100 \%\end{array}$ & $\begin{array}{r}\text { Seca suave } \\
\text { Seca }\end{array}$ \\
\hline
\end{tabular}

Fonte: Fernandes et al., (2009).

\section{Resultados e Discussões}

Para a série histórica (1992 - 2012), aplicaram-se aos 252 meses à equação (Índice de Porcentagem Normal) que classificou os meses de toda a série (Quadro 1), cuja média de chuva para os 22 meses classificados como extremamente úmidos foi $333,5 \mathrm{~mm}$, sendo que o maior volume registrado foi em janeiro de 1996, com 468,0 mm, o menor foi em abril de 2012 com 262,0 mm. Desse total, 69,1\% das chuvas foram classificadas como frontal e 30,9\% convectivas. As chuvas frontais são aquelas registradas durante a passagem dos sistemas frontais pela região, para os demais registros foram considerados chuvas convectivas.

Na série, o maior número do mesmo mês extremamente úmido foi janeiro, cinco no total, classificados para os anos de 1995, 1996, 2002, 2005 e 2010; o segundo foi fevereiro, três no total, registrados nos anos de 1999, 2000 e 2003. Março não apresentou. Mesmo assim, 36,4\% dos meses classificados como extremamente úmidos ocorreram na estação do verão.

Nessa região, o verão é a estação mais úmida, portanto, espera-se que o número de meses extremamente úmido também seja largamente superior aos verificados nas demais estações, no entanto, do total de 22 classificados, oito ocorreram na estação do verão (Quadro 1). Do total de meses classificados como extremamente úmidos $36,4 \%$ foram na estação do verão.

Para a estação do outono, foram seis meses classificados como extremamente úmidos, abril de 1998 e de 2012, maio de 1992, 2002 e 2004 e junho de1997. Ao considerar todos esses meses, apuraram-se que $27,3 \%$ dos meses classificados como extremamente úmidos, ocorreram na estação do outono.

O outono é uma estação de transição para a região. Os sistemas de baixa pressão, gradativamente recuam para o Centro Oeste e os sistemas de alta pressão, representados pela massa Polar atlântica avançam com mais frequência e às vezes pelo interior do continente (BORSATO, 2010).

\begin{tabular}{|c|c|c|c|c|c|c|c|c|c|c|c|c|}
\hline $\begin{array}{c}\text { Meses } \\
\text { / anos }\end{array}$ & 01 & 02 & 03 & 04 & 05 & 06 & 07 & 08 & 09 & 10 & 11 & 12 \\
\hline 1992 & & & & & & & & & & & & \\
\hline 1993 & & & & & & & & & & & & \\
\hline 1994 & & & & & & & & & & & & \\
\hline 1995 & & & & & & & & & & & \\
\hline 1996 & & & & & & & & & & & \\
\hline 1997 & & & & & & & & & & & & \\
\hline 1998 & & & & & & & & & & & & \\
\hline
\end{tabular}




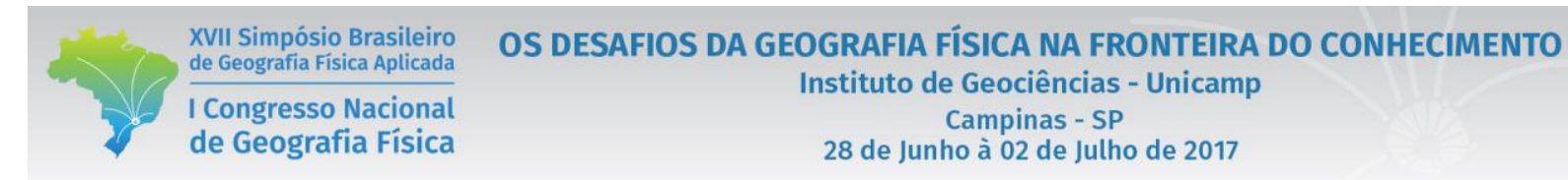

\begin{tabular}{|l|l|l|l|l|l|l|l|l|l|l|l|}
\hline $\mathbf{1 9 9 9}$ & & & & & & & & & & & \\
\hline 2000 \\
\hline 2001
\end{tabular}

Quadro 1 - Classificação Índice de Porcentagem Normal para a série 1992 - 2012.

Tabela I: Faixas em porcentagens com a classificação segundo o "Índice de Porcentagem Normal" de $10 \%$ até $100 \%$ acima da média (normal Climatológica) há cinco classes. De $10 \%$ a $100 \%$ abaixo da média há também cinco classes.

\begin{tabular}{|c|c|c|c|}
\hline PN* & Classificação & PN* & Classificaçã \\
\hline$\geq 100 \%$ a $90 \%$ & Extremamente úmido & $-10 \%$ a $29,9 \%$ & Seca inicial \\
\hline $70 \%$ a $89,9 \%$ & Umidade alta & $-30 \%$ a $49,9 \%$ & Seca suave \\
\hline $50 \%$ a $69,9 \%$ & Umidade moderada & $-50 \%$ a $69,9 \%$ & Seca moderada \\
\hline $30 \%$ a $49,9 \%$ & Umidade baixa & $-70 \%$ a $89,9 \%$ & Seca severa \\
\hline $10 \%$ a $29,9 \%$ & Umidade inicial & $-90 \%$ a $\leq-100 \%$ & Seca extrema \\
\hline$-9,9 \% \leq 0 \leq 9,9 \%$ & Normal & & \\
\hline
\end{tabular}

A estação do inverno é seguramente a menos úmida na região e a classificação segundo o Índice de Porcentagem Normal confirmou, somente um mês foi classificado como extremamente úmido, setembro em 1998, ou seja, 4,5\% da série.

A estação da primavera é, para a região de Campo Mourão a segunda estação de transição, com variação brusca nos estados do tempo. Borsato (2010) estudou a dinâmica das massas de ares para essa região e verificou que a primavera é uma estação de transição onde, ora o tempo é comandado por sistemas de baixa pressão, ora pelos de alta. As chuvas escassas e irregulares do inverno tornam-se mais frequentes e gradativamente as do tipo frontal vão sendo substituídas pelas convectivas, as mais comuns na estação do verão.

Na estação da primavera as chuvas são irregulares e o mês de setembro conserva as características pluviais do inverno. Segundo a classificação foram três outubros extremamente úmidos, 2004, 2005 e 2009, novembro, somente um, 2007 e dezembro três, 1994, 1996 e 2010. Na estação, 31,8\% dos meses da série foram classificados como extremamente úmidos. 


\section{OS DESAFIOS DA GEOGRAFIA FÍSICA NA FRONTEIRA DO CONHECIMENTO \\ Instituto de Geociências - Unicamp \\ Campinas - SP \\ 28 de Junho à 02 de Julho de 2017}

\subsection{Análise para o mês de janeiro de 1995:}

Dos cinco janeiros classificados como extremamente úmidos, o janeiro de 1995 foi o primeiro, com altura de 356,4 mm. Para o Instituto Nacional de Meteorologia, a média para o mês de janeiro é de 187,7 mm (INMET, 2016). Dessa forma, a chuva registrada foi praticamente o dobro da Normal Climatológica para a região.

Prevaleceram para o mês, chuvas do tipo frontal com $61,8 \%$, os sistemas frontais atuaram em $29,0 \%$ do tempo cronológico, o que explica a elevada precipitação ocasionada pela passagem dos sistemas pela região.

A massa Equatorial continental prevaleceu no tempo cronológico deste mês, atuando em 37,1\%. Essa massa de ar é a mais importante no elemento umidade, pois a baixa pressão e as elevadas temperaturas favorecem a intensificação das correntes convectivas, precipitações e elevada taxa de umidade, por isso, durante o período de atuação, os episódios de chuvas convectivas são comuns. As outras massas de ares que também atuaram na região nesse mês foram a massa Tropical continental com 30,6\% do tempo cronológico e a massa Polar atlântica com apenas 3,2\% de atuação, a Tropical atlântica não atuou.

As análises da dinâmica das massas de ares na região mostraram que a elevada precipitação foi consequência da intensa participação dos sistemas frontais, e da participação da massa Equatorial continental, ambas responsáveis por chuvas intensas.

Para os demais meses foram realizados o mesmo procedimento metodológico; a quantificação dos sistemas atmosféricos e os resultados foram organizados na Tabela 2. Ela mostra as participações dos sistemas atmosféricos para os meses classificados como extremamente úmidos, como já foi comentado, os meses mais quentes são, geralmente aqueles que recebem os maiores volumes de chuva. Portanto houve meses nas estações do outono e da primavera e em quantitativo oscilou próximo ao classificado na estação do verão. Essa irregular distribuição é característica de zona de transição climática.

Tabela 2 - Sistemas Atmosféricos atuantes em Campo Mourão em (\%)

\begin{tabular}{ccccccccc}
\hline Ano & $\mathrm{SF}(\%)$ & $\mathrm{mPa}(\%)$ & $\mathrm{mTa}(\%)$ & $\mathrm{mTc}(\%)$ & $\mathrm{mEc}(\%)$ & Chuva(mm) & Frontal(\%) & Conv.(\%) \\
\hline Jan/1995 & 29,0 & 3,2 & 0,0 & 30,6 & 37,2 & 356,4 & 61,8 & 38,2 \\
Jan/1996 & 17,7 & 3,2 & 1,6 & 46,8 & 30,7 & 468,0 & 39,8 & 60,2 \\
Jan/2002 & 17,7 & 22,6 & 3,2 & 38,8 & 17,7 & 281,1 & 42,8 & 57,2 \\
Jan/2005 & 17,7 & 9,7 & 0,0 & 22,6 & 50,0 & 319,1 & 48,3 & 51,7 \\
Jan/2010 & 17,7 & 11,3 & 6,5 & 16,1 & 48,4 & 276,4 & 45,7 & 54,3 \\
Fev/1999 & 14,3 & 8,9 & 1,8 & 5,4 & 69,6 & 274,2 & 42,8 & 57,2 \\
Fev/2000 & 17,3 & 19,0 & 1,7 & 37,9 & 24,1 & 356,8 & 46,2 & 53,8 \\
Fev/2003 & 19,6 & 12,5 & 16,1 & 14,2 & 37,6 & 262,4 & 80,1 & 19,9 \\
Abr/1998 & 13,3 & 46,7 & 11,7 & 28,3 & 0,0 & 441,1 & 94,6 & 5,4 \\
Abr/2012 & 13,3 & 36,7 & 41,7 & 8,3 & 0,0 & 262,0 & 99,4 & 0,6
\end{tabular}


XVII Simpósio Brasileiro de Geografia Fisica Aplicada

I Congresso Nacional

de Geografia Física

OS DESAFIOS DA GEOGRAFIA FÍSICA NA FRONTEIRA DO CONHECIMENTO

Instituto de Geociências - Unicamp

Campinas - SP

28 de Junho à 02 de Julho de 2017

\begin{tabular}{ccccccccc} 
Mai/1992 & 21,0 & 41,9 & 14,5 & 22,6 & 0,0 & 378,8 & 98,1 & 1,9 \\
Mai/2002 & 3,2 & 33,9 & 56,4 & 6,5 & 0,0 & 376,9 & 73,7 & 26,3 \\
Mai/2004 & 29,0 & 54,9 & 0,0 & 4,8 & 11,3 & 287,1 & 99,7 & 0,3 \\
Jun/1997 & 18,3 & 50,0 & 26,7 & 5,0 & 0,0 & 328,5 & 78,8 & 21,2 \\
Set/1998 & 16,7 & 45,0 & 23,3 & 15,0 & 0,0 & 382,2 & 75,1 & 24,9 \\
Out/2004 & 29,0 & 56,4 & 0,0 & 8,1 & 6,5 & 311,1 & 100,0 & 0,0 \\
Out/2005 & 27,4 & 21,0 & 0,0 & 16,1 & 35,5 & 346,7 & 77,0 & 23,0 \\
Out/2009 & 21,0 & 35,4 & 0,0 & 22,6 & 21,0 & 334,4 & 74,6 & 25,4 \\
Nov/2007 & 21,7 & 31,6 & 0,0 & 35,0 & 11,7 & 269,9 & 78,4 & 21,6 \\
Dez/1993 & 24,2 & 12,9 & 0,0 & 32,3 & 30,6 & 289,3 & 80,8 & 19,2 \\
Dez/1996 & 14,5 & 8,1 & 6,5 & 62,8 & 8,1 & 387,2 & 63,8 & 36,2 \\
Dez/2010 & 9,7 & 4,8 & 0,0 & 74,2 & 11,3 & 346,4 & 24,1 & 75,9 \\
Média & 18,8 & 25,9 & 9,6 & 25,2 & 20,5 & 333,5 & 69,3 & 30,7 \\
\hline
\end{tabular}

Para os meses mais quentes, o volume que excedeu as Normais Climatológicas foi consequência das chuvas frontais, ou seja, as chuvas convectivas ocorreram próximo do esperado para esses meses, como os sistemas frontais aumentaram suas participações, o volume foi excessivamente acima do esperado.

Para o mês de inverno classificado, o excesso de chuva foi consequência de frente estacionária1, ou seja, há episódios em que os sistemas frontais estacionaram sobre o norte do Paraná e o estado do tempo chuvoso se estende ao período em que a frente se mantiver sobre a região.

Os meses chuvosos classificados nas estações intermediárias, outono e primavera receberam incremento de chuva, consequência de mais sistemas frontais avançando pela região e as vezes também o estacionamento de algumas frentes.

\section{Considerações Finais}

A região de Campo Mourão localiza-se em uma ampla faixa de transição climática, a qual sofre as oscilações sazonais e interanuais intensas, por isso também, na série histórica estudada tivemos anos em que a altura da chuva extrapolou 2000,0 $\mathrm{mm}$ e em anos de menor pluviosidade a altura foi inferior $1350,0 \mathrm{~mm}$. Essa ampla variabilidade interanual também se verifica para as estações do ano.

O verão é a estação mais úmida e o inverno mais seca. Dos 252 meses analisados, 22 foram classificados como extremamente úmidos, onze ocorreram nos meses mais quentes (dezembro, 3 meses, janeiro, 5 e fevereiro 3), por outro lado, na estação do inverno apenas um setembro foi classificado com extremamente úmido.

\footnotetext{
${ }^{1}$ Frente estacionária - Quando não há o avanço do ar frio nem o avanço do ar quente relativamente uma ao outro, gera-se entre eles uma frente estacionária. A precipitação associada é geralmente leve e estratiforme, mas pode tornar-se bem significativa se a frente permanecer estacionária por muito tempo (USP, 2017).
}

DOI - 10.20396/sbgfa.v1i2017.2384 - ISBN 978-85-85369-16-3 
Com relação a gêneses das chuvas, as frontais contribuíram com 69,3\%. Dessa forma, constata-se que a elevada pluviosidade ocorreu por contribuições frontais. Para essa região, as chuvas, na estação do inverno são essencialmente frontais (BORSATO, 2006). Para o mês de setembro classificado como extremamente úmido verificou-se que episódios de frente estacionários contribuíram para a elevação do volume de chuva.

Observou-se também que houveram verões em que a Zona de Convergência do Atlântico Sul (ZCAS) bordejou o norte do Paraná e contribui no incremento das chuvas.

Para as estações intermediárias, outono e primavera, totalizaram 13 meses extremamente úmidos e para todos esses, as chuvas frontais prevaleceram. Houveram meses em que o número de sistemas frontais foi acima da média, em outros, eles estacionaram sobre a região de estudo, por isso, o tempo cronológico de participação foi amplo. O exemplo mais evidente foi maio de 2002. Naquele mês os sistemas frontais participaram em apenas 3,2\% do tempo cronológico e as chuvas frontais somaram $277,9 \mathrm{~mm}$.

Com relação à participação dos sistemas atmosféricos, como já era esperado. Na estação mais fria prevaleceu a atuação da massa Polar atlântica. Para a estação mais quente prevaleceu a atuação da massa Equatorial continental e da massa Tropical continental.

De forma geral, os resultados evidenciam a transitoriedade climática da região, evidenciados pela distribuição dos meses extremamente úmidos não concentrados em uma estação. Dessa forma, as estações do verão e da primavera foram as mais úmidas, num universo de 252 meses, 15 foram verificados nessas duas estações.

\section{Agradecimentos}

A publicação e apresentação deste trabalho foi financiado pela Fundação Araucária de Apoio ao Desenvolvimento Científico e Tecnológico do Estado do Paraná. EDITAL 05/2016 - PRPPG/Unespar Apoio à Participação de Docentes em Eventos Científicos.

\section{Bibliografia}

BORSATO, V. A. A participação dos sistemas atmosféricos atuantes na bacia do Auto Rio Paraná no período de 1980 a 2003. 2006. Tese (Doutorado em Ciências Ambientais) - Nupélia, UEM, Maringá.

BORSATO, V. da A. A participação dos sistemas atmosféricos atuantes na bacia do rio Paraná no período 1980 a 2003. Revista Brasileira de Climatologia. Associação Brasileira de Climatologia. Presidente Prudente. SP. Ano 6 - V.07, pp. 87-102, 2010.

CASTRO, A. L. C. Glossário de defesa civil: estudo de riscos e medicina de desastres. Brasília: MPO/ Departamento de Defesa Civil, 1998. 283 p.

CAVALCANTI, I. F. Casos de intensa precipitação nas Regiões Sul e Sudeste do Brasil no período de inverno de 1979 a 1983. São José dos Campos: INPE, 1985. (INPE- 3743-RPE/498). 
FERNANDES, D. S.; HEINEMANN, A. B.; PAZ, R. L. da; AMORIM, A de O.; CARDOSO, A.S. Índices para a quantificação das secas. Documento 244. Embrapa Arroz e Feijão, Santo Antônio de Goiás, Goiás, 2009, p. 49.

FERREIRA, C. C. Ciclogêneses e ciclones extratropicais na Região Sul-Sudeste do Brasil e suas influências no tempo, INPE-4812-TDL/359, 1989. p. 93.

INSTITUTO NACIONAL DE METEREOLOGIA. Normal Climatológica do Brasil 1961 - 1990. Brasília - DF. Disponível em: <http://www.inmet.gov.br/portal/index.php?r=clima/normaisclimatologicas>. Acesso em: 23 de março 2016.

LAMPARELLI, M. C. Grau de Trofia em corpos d’água do Estado de São Paulo. Tese. Sc., Universidade de São Paulo. São Paulo, Brasil, 2004.

MAR-MIL MARINHA DO BRASIL. Cartas Sinóticas. Disponível em: <http://www.mar.mil.br/dhn/chm/meteo/prev/cartas.htm>. Acesso em: 04 dezembro de 2016.

MONTEIRO, C.A. de F. O clima da Região Sul. In: Geografia regional do Brasil: Grande Região Sul. Rio de Janeiro: IBGE/ Conselho Nacional de Geografia, 1968. v. 4 p. 117-169.

NIMER, E. Climatologia da Região Sul do Brasil. In: Revista Brasileira de Geografia. Introdução a Climatologia Dinâmica. Rio de Janeiro: IBGE, v33 n. 4. p. 3 - 65. 1971.

PÉDELABORDE, P.Introduction a l'étudescientifiqueduclimat. Paris: Sedes, 1970. 352 p.

VAREJÃO-SILVA M. A. Meteorologia e Climatologia. Instituto Nacional de Meteorologia Brasília, DF, 2000 p. 515 .

VIANELLO, R. L., Meteorologia básica e aplicações. Universidade Federal de Viçosa. Editora UFV, 2000. p. 449.

VIEIRA, S. R.; LOMBARDI NETO, F.; BURROWS, I.T. Mapeamento da chuva diária máxima provável para o estado de São Paulo. Revista Brasileira de Ciências do Solo, 15:93-98, 1991. 